\title{
Chapter 5 \\ Queen Physics: \\ How Much of the Globe is Painted Red?
}

\author{
Nancy Cartwright and Eric Martin ${ }^{1}$
}

\section{Prelude}

This paper has two authors. We begin with Nancy Cartwright's account of the hodgepodge of nature. Much of this account is shared with John Polkinghorne, which is why we have the honor of contributing to this volume in tribute to him. In the next section Eric Martin explains some of Polkinghorne's ideas on order in nature and shows how Cartwright's ideas sometimes mesh with these but sometimes do not.

\section{The Hodgepodge of Nature}

Despite all of the apparent differences we see among the unlimited number of things that happen in the world, there is but one realm, we are told, and physics is its queen. I reject this claim. There is not one realm, as the ambassadors of physics maintain, nor two, as mind-body dualists proclaim, but many: cooperating, quarrelling and negotiating. I reject the universal rule of physics not because I dissent from her dictates but because I respect her strengths. What physics can do, she does exceedingly well. However, her very strengths suggest that she cannot rule everything with the same iron hand, nor can she do it alone.

I adopt this position as an empiricist. As an empiricist I maintain that our best guide to the structure of nature is how our sciences work when they work best. We do not use only physics to build a laser. So why suppose that Nature behaves differently? An empiricist stance maintains that the way to learn about the structure of nature is to look at it, and when it comes to the parts of the world studied by physics, our best lens for looking at them is through our most successful accounts in physics. When I look through that lens, I see a quite different world from one where physics reigns, supremely and by herself. I see a dappled world with a

1 The authors would like to thank the Templeton Foundation for their support of the ongoing research project, “God’s Order, Man’s Order, and the Order of Nature.” 
hodgepodge of different kinds of features interacting in a variety of different ways. ${ }^{2}$ This is true even for the effects that physics herself is supposed to control.

The sciences give us the best basis for our beliefs about nature. However, it is what the sciences need as they are used to predict and manipulate the empirical world that we have warrant for believing in. These uses in fact rely on an enormous number of concrete, diverse, complicated and particular laws-hardly just a few high-level fundamental principles of physics.

Consider French physicist, historian of physics and Catholic apologist, Pierre Duhem, writing in 1906 on The Aim and Structure of Physical Theory. Duhem argued that there are two kinds of minds: ample and deep. The ample mind "analyzes an enormous number of concrete, diverse, complicated, particular facts, and summarizes what is common and essential to them in a law, that is, a general proposition tying together abstract notions." 3 The deep mind "contemplates a whole group of laws; for this group it substitutes a very small number of extremely general judgements referring to some very abstract idea.” This is the French mind. Duhem explained: "In every nation we find some men who have the ample type of mind, but there is one people in whom this ampleness of mind is endemic; namely, the English people." 4

Writing in How the Laws of Physics Lie, in 1983 I urged that God has the mind of the English. If this is the way the English can do science, why should it not be the way nature does it too? However, today I think that, moreover, it is the mind of an English engineer! That is a thesis we shall come to later. For now let us consider just the substitution of a few abstract general principles for the myriad concrete detailed ones that we use on the ground to model and manipulate nature.

It is a mistake to think that the language of high theory can be a substitute for all those diverse concrete laws to which Duhem referred. In trying to fit the concrete laws into its own framework, the high theory substitution:

- distorts many of them;

- omits much of their information;

- ignores many of them; and

- overstretches its own abstract vocabulary.

Trying to fit so many laws into the high theory of abstract ideas is trying to pack too much into too little. High theory cannot accommodate the plenitude of concrete and particular principles that are necessary to get the details just right to get a laser to work or a superconducting quantum interference device (SQUID) to test whether a patient has had a stroke.

2 Nancy Cartwright, Dappled World, Cambridge, Cambridge University Press, 1999.

3. Pierre Duhem, The Aim and Structure of Physical Theory, Princeton, NJ, Princeton University Press, 1954 [1906], p. 55.

4 Ibid., p. 63. may not be placed on any publicly accessible or commercial servers. 
While at Stanford University, I was enamored with quantum physics and, being a committed empiricist, particularly with the startling empirical successes that speak for its credibility, especially lasers and superconductors, which I made a special area of study. I was especially impressed simultaneously by how crucial quantum considerations are for understanding these devices and by how little they can do by themselves. They must be combined with huge amounts of classical physics, practical information, knowledge of materials and exceedingly careful and clever engineering before accurate predictions emerge, and none of this is described - or looks as if it is even in principle describable - in the language of quantum physics. ${ }^{5}$ Physics can measure, predict and manipulate the world in precise detail, but the knowledge that produces our extraordinarily precise predictions and our astounding devices - the very knowledge that gives us confidence in the laws of physics - is not all written in the language of physics, let alone in one single language of physics. Its wellspring is what I call "the scientific Babel."

I was clearly influenced in these views not only by what I saw in the building of lasers and the exploitation of SQIDS but also by my hero Otto Neurath. Neurath spearheaded the unity of science movement of the Vienna Circle. However, his idea of unity was not that physics - or anything else for that matter-could produce predictions by herself. He argued for unity at the point of action. His idea was that we must bring the requisite sciences together as best we can, each time anew, to achieve the projects we set ourselves, from building a laser or a radar to even - as Neurath believed we had the intellectual resources for-organizing and controlling the roller-coaster of the economy. Although he urged us to talk the same language wherever possible, he never believed that this language would stretch far or last long or capture much of what the separate users mean by its terms. Neurath advocated not a shared language but a "universal jargon."” This idea has recently been taken up and defended with a vengeance in Science Studies.

Consider the Massachusetts Institute of Technology World War II radar project. Designing the radar took the united efforts of mathematicians, physicists, engineers and technicians, each themselves expert in one small domain with a language of its own, put together by the urgency of war and often against their will. It took a year for them to be able to communicate well enough to build a usable device, and redesign the physical environment. The building used to be arranged floorby-floor according to prestige, with mathematicians at the top. The radar project mixed researchers from the different disciplines at long tables on each floor, tables that reflected in their very geometry the five components of the radar to be built. Success was achieved not by constructing a single language nor by translation, but by face-to-face contact that allowed enough interchange to make a go of it.

5 Nancy Cartwright, How the Laws of Physics Lie, Oxford, Clarendon Press, 1983.

6 Nancy Cartwright, Jordi Cat, Lola Fleck and Thomas E. Eubel, Otto Neurath: Philosophy Between Science and Politics, Cambridge, Cambridge University Press, 1996. 
Peter Galison calls this space of interchange the "trading zone."7 Consider theoretical and experimental physicists treating what we like to think of as the very same phenomenon. Galison pictures this as very often like two tribes stuck in linguistic isolation. They trade in the "commerce" of vital "shared" concepts, but each group in this trade maintains its own understanding of these concepts within itself, and even these internal understandings may be out of kilter in various ways. Otherwise they would not be able to produce the detailed wellfounded results needed for their own projects to succeed. They speak Neurath's universal jargon or what Peter Galison describes as a kind of pidgin, with each group maintaining different understandings of the terms they use in common. According to Galison this is often the case for theoretical and experimental physicists, even with respect to the very same claim, a claim the theoreticians derive and the experimentalists test.

Other scholars in Science Studies see the same thing. Sang Wook Yi's study of thermodynamics ${ }^{8}$ rejects the usual story that it reduces to statistical mechanics. He argues that a more useful way of understanding the relationship is as collaboration and competition among alternative methodologies rather than reduction of one theory to another. The theme of cooperation and competition carries over from Yi's work on condensed matter physics, where he shows how it plays a crucial role in generating the right kind of models for systems with many bodies.

Marilena Di Bucchianico writes about the quarrelling camps in hightemperature superconductivity. ${ }^{9}$ It seems that they do not share a common meaning for the same terms even in this single narrow domain. For example, the "kink" is an observed and unexpected spike in the dispersion curve during photoemission studies. Using the same word, different groups construct the kink differently from the same body of data. Or take the phase diagram, a type of chart that shows conditions under which thermodynamically distinct phases occur. Often, each camp builds and presents its own phase diagram, which contains only a selection of observed features, thus creating a vast series of almost incommensurable theorizations.

Hasok Chang's important study ${ }^{10}$ of the long struggle to measure temperature makes it clear how essential were contributions from potters, experimentalists with specialisms from thermal physics to glassblowing, chemists, doctors, physicists from the most abstruse theoreticians to the most down-to-earth instrument builders, famous inventors, entrepreneurs, soldiers and myriad others.

7 Peter Galison, Image and Logic: A Material Culture of Microphysics, Chicago, IL, University of Chicago Press, 1997.

8 Sang Wook Yi, "Reduction of Thermodynamics: A Few Problems," Philosophy of Science 70(5) (2003), pp. 1028-38.

9 Marilena Di Bucchianico, Modelling High Temperature Superconductivity: A Philosophical Inquiry into Theory, Experiment and Dissent, PhD Dissertation, London School of Economics, 2009.

10 Hasok Chang, Inventing Temperature, Oxford, Oxford University Press, 2007. 
Harry Collins in his study of gravity-wave experiments ${ }^{11}$ concludes that gravity waves are "boundary objects" - understood and valued differently by the different cultural groups that share them. Alternatively, look at the study of the original BCS model of superconductivity by Cartwright, Tomar and Suarez. ${ }^{12}$ This model was the first successful theoretical account of the phenomenon, a tour de force of quantum modelling, which still lies at the heart of our understanding of superconductivity. Although it has been tidied up considerably, it remains a hodgepodge of high quantum theory and ad hoc assumptions grounded in classical electromagnetic theory.

So science is conducted within a Babel of languages, drawing on expertise from different corners of research. Why suppose the Book of Nature is written in a single language when science is not? The problem is not unity at the "high" end-the grand unity in one mathematical theory that many physicists long for. Rather, the problem is unity at the "low" end-where physics finally engages with the empirical world. There, unity is a superstition.

If we are to extrapolate from our knowledge of science to an understanding of nature, the metaphysical significance of these considerations is novel and has not been sufficiently appreciated. To appreciate the consequences of this view it is helpful to recall some of the positions it might oppose. Take, for example, recent work from Lydia Jaeger, ${ }^{13}$ which supposes that God's wisdom demands order and comprehensibility, that comprehensibility entails order and that order entails the immutable rule of law. I dispute all three claims.

The scientific world view articulated by Jaeger and a host of others is that science will slowly reveal, hidden within the all-too-apparent mess, a truer and more fundamental reality that is beautiful, clean and entirely orderly. This tidy image of nature is governed thoroughly by laws: essentially those of high theory physics. Physics, then, ends up as the ultimate arbiter of reality, her sparse laws pervading and ordering the natural world. This familiar image of nature dates at least to the scientific revolution and remains influential. ${ }^{14}$ For all of our advances, the image of an orderly, deterministic, clockwork universe, with its roots in a particular vision of monarchical divine governance, has been surprisingly enduring.

I have not been alone in questioning that traditional world view. The abundance of recent scholarship in Science Studies constitutes a quiet revolution in terms of the received view of natural order. This scholarship is not about the standard philosophical question of realism and anti-realism in science. The questions at

11 Harry Collins, Gravity’s Shadow, Chicago, IL, University of Chicago Press, 2004.

12 Nancy Cartwright, Towfic Shomar and Maricio Suarez, "The Tool Box of Science: Tools for the Building of Models with a Superconductivity Example," Poznan Studies in the Philosophy of the Sciences and the Humanities 44 (1995), pp. 137-49.

13 Lydia Jaeger, Einstein, Polanyi, and the Laws of Nature, West Conshohocken, PA, Templeton Press, 2010.

14 Stephen Weinberg, Dreams of a Final Theory: The Search for the Fundamental Laws of Nature, New York, Vintage Books, 1993. 
hand are more precisely about dominion-how far the reach of physics' laws extends (or any laws for that matter) —and autocracy — whether physics reigns supreme and by herself, or is one part of a more motley assembly of sciences. The studies mentioned above suggest that physics is not even an autocrat in her own domain, much less autocratic across all of nature. The answer that physics might be just one among many sciences is a revolution in terms of our thinking about the relationship among the sciences and about the order of nature. ${ }^{15}$

If my story, or something like it, is true, and nature does not fit the old image of law-governed order, whither then order and comprehensibility? Is it still possible to speak intelligibly about the creator of such a world at all, much less a rational creator? I imagine God as an engineer, not as a mechanic, as the Mechanical Philosophy would have it, where those terms are intended in what Norton Wise picks out as their nineteenth-century sense. ${ }^{16}$ For instance, the English mathematician and engineer Charles Babbage divided objects of machinery into engines, employed to produce power, and mechanisms, merely to transmit force and execute work. While engines implied productive power, "mechanism," in this more specific sense, referred to a device for executing a typically repetitive motion. Engineers use principles about how things behave in special circumstances to construct devices that give rise to regular behavior, where those principles are not necessarily universal laws. I suppose that God is like an engineer, not a mechanic, and order, where it exists in nature, results from clever engineering.

This metaphysical picture is in many ways more modest than the received scientific world view. It suggests only that the world is as our sciences are, and that order, where it exists, arises from good engineering, whether God's or our own. Such order need not be universal or necessary, and yet the world, or at least some parts of it, remains comprehensible.

A ready response can be made to this mass of evidence from Science Studies if you believe in the autocratic powers of physics, despite her repeated failure to rule by herself in even the best of circumstances: blame it on us, not her. This standard response draws a line between epistemology and metaphysics, and insists that, really, the world is totally ordered under the rule of universal law, and it is only our limited (post-lapsarian) knowledge that is failing. The world is totally ordered; it is just us weak intellects who have so far produced only an incomplete and inadequate approximation to what Queen Physics is really accomplishing.

Yet that is hardly the simplest or most natural conclusion to draw from the evidence. If we speculate about the structure of Nature, as empiricists we had better stick as close to the evidence as possible. Moreover, the standard response is an unattractive metaphysical conclusion, on several fronts. Nothing ever happens in a mechanical world under the universal rule of law; genuine novelty and creativity

15 Miriam Thalos, Without Hierarchy: An Essay on the Scale of Freedom in the Universe, forthcoming.

16 M.N. Wise, "The Gender of Automata in Victorian Britain,” in Jessica Riskin, ed., Genesis Redux, Chicago, IL, Chicago University Press, 2007. may not be placed on any publicly accessible or commercial servers. 
are nowhere found. A single time-slice contains all the information about the past and the future. Is God then a mechanic in this sense? As H.G. Wells's Time Traveller ${ }^{17}$ teaches, "There is no intelligence where there is no change and no need to change.” Why would the Deity create such a boring universe?

An engineered universe, on the other hand, suggests several fruitful and attractive alternatives. It provides a new aesthetic, a new view of nature, new questions about God, and new questions about the human role in nature. It suggests an aesthetic based on diversity and variety rather than uniformity. It suggests that nature is piecemeal and more like a hodgepodge than a solid color. Far from the austerity described by one set of fundamental laws dictating the motions of the world's machinery, this alternative is an abundant and plentiful universe, and in the tradition of natural theology, this could make for an important component in thinking about the character of the world's creator. It therefore contains new theological questions: what kind of God prefers a hodgepodge to hegemony? Further, there are new queries about us humans. Is it our job to build order? What kind of order? What counts as order, beauty or perfection?

\section{Polkinghorne’s Bottom-up Thinking}

John Polkinghorne shares a commitment to empiricism and to bottom-up thinking; his Gifford Lectures were even subtitled Reflections of a bottom-up thinker. ${ }^{18}$ This empirically motivated outlook has guided Polkinghorne's work on science and religion in several ways. Most generally, he insists that science be taken very seriously and incorporated into theological reflection, whose vision has too often been parochially restricted to humanity. ${ }^{19}$ Polkinghorne urges that the deliverances of natural science become a part of that vision, a view congenial to any empiricist.

Secondly, while recognizing certain built-in limitations to its objectivizing epistemology, Polkinghorne believes that science is the best way to learn about the natural world. "[W]hy go to all the trouble involved in doing science if one does not believe that thereby we are learning what the physical world is actually like?" ${ }^{20}$ Polkinghorne counts himself a "critical realist" who believes that the wellconfirmed products of science can count as progress towards truth. Cartwright agrees.

Thirdly, Polkinghorne writes about how scientific knowledge informs important debates in epistemology and metaphysics. From his own study of quantum mechanics, Polkinghorne draws the conclusion that "there is no universal

17 H.G. Wells, The Time Machine, an Invention. London, William Heinemann, 1895.

18 John Polkinghorne, The Faith of a Physicist; Reflections of a Bottom-up Thinker: the Gifford Lectures for 1993-4, Princeton NJ, Princeton University Press, 1994.

19 Ibid., p. 5.

20 John Polkinghorne, Science and the Trinity, London, Yale University Press, 2004, p. 79. 
epistemology, no single sovereign way in which we hope to gain knowledge.”21 This insight runs counter to the tradition which says that there is only one Scientific Method, whose application is definitive of science. Polkinghorne also calls this "epistemic specificity," 22 arguing that physics alone does not suffice to tell us about the complete structure of reality. Polkinghorne points out the need for theology in addition to physics, but his argument holds equally well for the incorporation of other sciences. On top of Polkinghorne's detailed attention to physics and theology, Cartwright urges greater attention to the interstices in this space of knowledge. The picture becomes yet more rich and complex when chemistry, biology and social sciences are added into the jumble.

Like Cartwright, Polkinghorne resists drawing the sharp line between epistemology and metaphysics that allows the postulation of a simple or monolithic Nature in the face of our complex and fragmented knowledge. His motto that "epistemology models ontology" testifies to the close connections between scientific insight and warranted belief about what exists. "[I]n forming our account of reality we should be open to all aspects of our encounter with it. Tidy schemes, produced by selective oversimplification and resulting in a neglect of part of the data, are not of any value.”23 Again, Cartwright heartily agrees.

Two of Polkinghorne's favored descriptions of nature are "subtle" and "veiled"-metaphors that imply that nature is neither reducible to a small number of mathematical equations nor fully describable in grand theoretical syntheses. They imply further that there is more to reality than our simplest, highly controlled physics experiments tell about it. Cartwright agrees that there is no single complete picture of nature, much less one yielded directly by physics.

All the same, Polkinghorne retains a traditional physicist's aesthetic about the pervasiveness of natural laws, their connection with God's mind and the total comprehensibility of nature. ${ }^{24}$ This is where the views of Cartwright and Polkinghorne depart most strongly. While Polkinghorne recognizes that much of our scientific knowledge is "patchy," 25 he is more likely to identify the reason for such patchiness as the incompleteness of science, whereas Cartwright and fellow travelers (e.g. Dupre ${ }^{26}$ ) have sought to articulate the metaphysical underpinnings of our piecemeal knowledge. They argue that our knowledge may well be patchy because that is an accurate reflection of the world's own patchiness.

21 John Polkinghorne, Quantum Theory: A Very Short Introduction, Oxford, Oxford University Press, 2002, p. 87.

22 Polkinghorne, Science and the Trinity, p. 77.

23 John Polkinghorne, Faith Science, and Understanding, London, SPCK, 2000, p. 24.

24 Polkinghorne, Science and the Trinity, pp. 12-13.

25 John Polkinghorne, Exploring Reality, London, Yale University Press, 2005, p. xii.

26 John Dupre, The Disorder of Things, Cambridge, MA, Harvard University Press, 1993. may not be placed on any publicly accessible or commercial servers. 
From the hints of pluralism in Polkinghorne's corpus come some surprising points of contact with Cartwright's work. ${ }^{27}$ They both realize that the breakdown of the traditional view of natural order has not been sufficiently appreciated. Polkinghorne has given greater attention to the role of indeterminism and the in-principle limits to human knowledge suggested by chaotic and quantum phenomena, while Cartwright has utilized case studies from the practice of several sciences to argue for nature's dappled construction. Both are at pains to generate alternatives to the deterministic, mechanical world view promulgated for so long in the name of science.

27 Eric Martin, "Polkinghorne and Cartwright on Pluralisam and Metaphysics," Theology and Science, forthcoming. 
Copyright material: You are not permitted to transmit this file in any format or media; it may not be resold or reused without prior agreement with Ashgate Publishing and may not be placed on any publicly accessible or commercial servers. 